\title{
Studies on genome size estimation, chromosome number, gametophyte development and plant morphology of salt- tolerant halophyte Suaeda salsa
}

Yan Cheng ${ }^{1+}$, Pan Yang ${ }^{1,2+}$, Lihua Zhao ${ }^{1,3}$, S. V. G. N. Priyadarshani ${ }^{1,2}$, Qiao Zhou ${ }^{1,2}$, Zeyun Li ${ }^{1,2}$, Weimin Li $i^{1,4}$, Junjie Xiong ${ }^{1,3}$, Zhibin Lin 1,2, Li Li ${ }^{1,2}$, Xinyu Huang ${ }^{1,2}$, Jindian Liu', Mohammad Aslam¹, Heming Zhao', Gang Li, ${ }^{1,5}$, Jinbiao Ma ${ }^{6}$, Lei Li $i^{1,7}$ and Yuan Qin ${ }^{1,3^{*}}$

\begin{abstract}
Background: Soil salinization and alkalization are among the major agricultural threats that affect crop productivity worldwide, which are increasing day by day with an alarming rate. In recent years, several halophytes have been investigated for their utilization in soil remediation and to decipher the mechanism of salt-tolerance in these high salt tolerant genetic repositories. Suaeda salsa is an annual halophytic herb in the family Amaranthaceae, displaying high salt and alkali-resistance and having nutritive value. However, the fundamental biological characteristics of this valuable plant remain to be elucidated until today.

Results: In this study, we observed the morphology and development of Suaeda salsa, including seed morphology, seed germination, plant morphology, and flower development. Using microscopy, we observed the male and female gametophyte developments of Suaeda salsa. Also, chromosome behaviour during the meiosis of male gametophyte was studied. Eventually, the genome size of Suaeda salsa was estimated through flow cytometry using Arabidopsis as reference.

Conclusions: Our findings suggest that the male and female gametophyte developments of Suaeda salsa are similar to those of the model plant Arabidopsis, and the diploid Suaeda salsa contains nine pairs of chromosomes. The findings also indicate that the haploid genome of Suaeda salsa is approximately $437.5 \mathrm{MB}$. The observations and results discussed in this study will provide an insight into future research on Suaeda salsa.
\end{abstract}

Keywords: Soil salinization, Suaeda salsa, Gametophyte, Chromosome, Genome

\section{Background}

Soil salinization and alkalization have adverse effects on agricultural land, leading to reduced soil fertility. In recent years, salinization and alkalization have emerged as a severe threat affecting crop production worldwide [1].

\footnotetext{
* Correspondence: yuanqin001@foxmail.com

${ }^{\dagger}$ Yan Cheng and Pan Yang contributed equally to this work.

'State Key Laboratory of Ecological Pest Control for Fujian and Taiwan Crops, College of Plant Protection, Fujian Provincial Key Laboratory of Haixia Applied Plant Systems Biology, Center for Genomics and Biotechnology, Fujian Agriculture and Forestry University, Fuzhou 350002, China

${ }^{3}$ State Key Laboratory for Conservation and Utilization of Subtropical Agro-Bioresources, Guangxi Key Lab of Sugarcane Biology, College of Agriculture, Guangxi University, Nanning 530004, China

Full list of author information is available at the end of the article
}

It is estimated that about $20 \%$ of the world's cultivated land and nearly half of all irrigated land are affected by salinity and alkalinity [2]. The saline-alkaline land is widely distributed in the regions of all major continents, mainly in Eurasia, Africa and the western part of the Americas [3]. China's cultivatable land is also severely threated by the salinization and alkalization. The total area of saline-alkaline land in China is about $3.6 \times 10^{7}$ ha, accounting for $4.88 \%$ of the available land base [4]. The matter is becoming more severe in northeast China, where the saline-alkaline meadow covers more than $70 \%$ of the land area [5]. All in all, the severity in the world is

(c) The Author(s). 2019 Open Access This article is distributed under the terms of the Creative Commons Attribution 4.0 International License (http://creativecommons.org/licenses/by/4.0/), which permits unrestricted use, distribution, and 
still expanding due to human activities and global climate changes [6].

Suaeda salsa (accepted name: Suaeda maritima subsp. salsa (L.) Soó) is a well-known salt and alkali-resistant, succulent halophyte in the family Amaranthaceae, which was first recorded in an ancient Chinese book "Jiu Huang Ben Cao" that enrolled the potential food plants to cope with famine during Ming dynasty. Suaeda salsa exhibits a high tolerance to salt and alkali stresses and grows very well under salt content more than $0.48 \%$ even without salt glands and bladders in its leaves [7]. The most suitable $\mathrm{NaCl}$ concentration for promoting its growth is 200 $\mathrm{mM}$, and there is no significant difference can be observed when it is treated with $400 \mathrm{mM} \mathrm{NaCl}$ and $10 \mathrm{mM}$ $\mathrm{NaCl}$ [8]. As a model salt-tolerant plant, a number of genes involved in salt tolerance such as SsHKT1, SsNHX1, SsCAX1 have been identified, and their functions analyzed [9-11]. Additionally, Suaeda salsa possesses good $\mathrm{Cd}, \mathrm{Pb}$ and $\mathrm{Mn}$ tolerance and could be considered as a hyperaccumulator for those heavy metals, reflecting its ecological value on recuperating heavy metals-contaminated soil [12]. In addition to the values mentioned above, Suaeda salsa has very high edible and medicinal values as well. It is an annual herb, with excellent palatability for domestic animals and has great value in Chinese traditional medicine [13]. The young leaves and stems of Suaeda salsa are a highly nutritious vegetable that contains abundant proteins, dietary fibre, vitamins, minerals, and flavonoids [14], The oil from Suaeda salsa seeds is also edible [15], and it is rich in fatty acids. 90.7\% of Suaeda salsa fatty acid is unsaturated. Furthermore, the relative content of unsaturated fatty acids is higher than the other cooking oils, among which, the terephthalic acid, 11-Hexadecenoic acid, and Linoleic acid from Suaeda salsa seeds are up to $0.82,0.45,68.74 \%$ respectively [16]. It has been documented that the seed oil of Suaeda salsa has the function of decreasing blood sugar and blood pressure, lowering blood cholesterol, developing disease immunity [17], Therefore, the oil produced from Suaeda salsa seeds is beneficial for human consumption [18]. In this case, biological researchers have been putting the focus on increasing its seed yield [19].

Considering the scientific and edible values of Suaeda salsa, a number of researches recently have been conducted in the scopes of understanding the salt-tolerance mechanism, medicinal use, and nutrient value $[1,14,20]$. However, the reports regarding the fundamental biological characteristics of Suaeda salsa are limited and not systematic. In this study, the plant and flower morphologies of Suaeda salsa were observed, and the developments of its female and male gametophytes were described. Furthermore, the genomic characteristics of Suaeda salsa concerning chromosome number and genome size were also investigated. These results will improve our understanding of Suaeda salsa for future research and its utilization for crop breeding programme.

\section{Results \\ Seed morphology and germination of Suaeda salsa}

In angiosperms, a seed is covered with pericarp, which consists of endocarp, mesocarp, and exocarp. The germination process of Suaeda salsa seeds has been simply observed in a recent report, in which the roles of gibberellins and abscisic acid in regulating the germination of Suaeda salsa under salt stress were revealed [21]. Here, we conducted an extensive observation of the germination process of Suaeda salsa seeds. The mature seeds of Suaeda salsa also consisted of thin fleshy mesocarp and exocarp. Endocarp is hard and thin with blackish colour. During germination, endocarp was split into two parts. This splitting can be easily observed after $24 \mathrm{~h}$ of germination and split becoming wider after $48 \mathrm{~h}$ of germination, allowing radical to grow easily (Fig. 1a-f). Careful observation of the endocarp surface showed the honeycomblike pattern (Fig. 1n). Having thin hard endocarp makes seed germination obstructed delaying the propagation process, which is required to meet the agricultural demand. When the pericarp was removed, seeds appeared flat, disc-shaped with a size of $1.8-2.1 \mathrm{~mm}$ in diameter. The seed has a thin brownish seed coat (Fig. 1g). Once the seed coat was removed, we observed a brown thin whitish colour layer consisted of starch, which turned to a blackish-blue colour when treated with $\mathrm{KI} / \mathrm{I}_{2}$ (Fig. 1m). With the start of germination, the seed coat and thin starchy layer started to disappear. At this stage, we observed mature germinating planospiral embryo that is the distinguishing feature in this plant family [22] (Fig. $1 \mathrm{~g}-\mathrm{l})$. The outermost end of the planospiral embryo act as radical, giving rise to root. The innermost end of the embryo act as plumule that later develops into the shoot. During Suaeda salsa seeds germination, we observed radical growth into roots first and then followed by two cotyledons appearance at the other end of the embryo. Later we observed the emergence of true leaves. This germination study revealed that the Suaeda salsa possesses epigeal germination pattern (Fig. 1o-s).

\section{Plant development and morphology of Suaeda salsa}

To understand the morphology of Suaeda salsa, we observed the plant architecture at five vegetative development stages. Fig 2 shows the whole plant (Fig. 2a) of 10-, 20-, 40-, 80-, and 100-days old Suaeda salsa grown in the greenhouse. Suaeda salsa plant has one main axis with branches of second-order (e.g. primary, secondary, tertiary branches). The leaves are flat to round cylindrical without recognizable petioles, and the branches emerge from 20 to 40 days without significant difference to the 


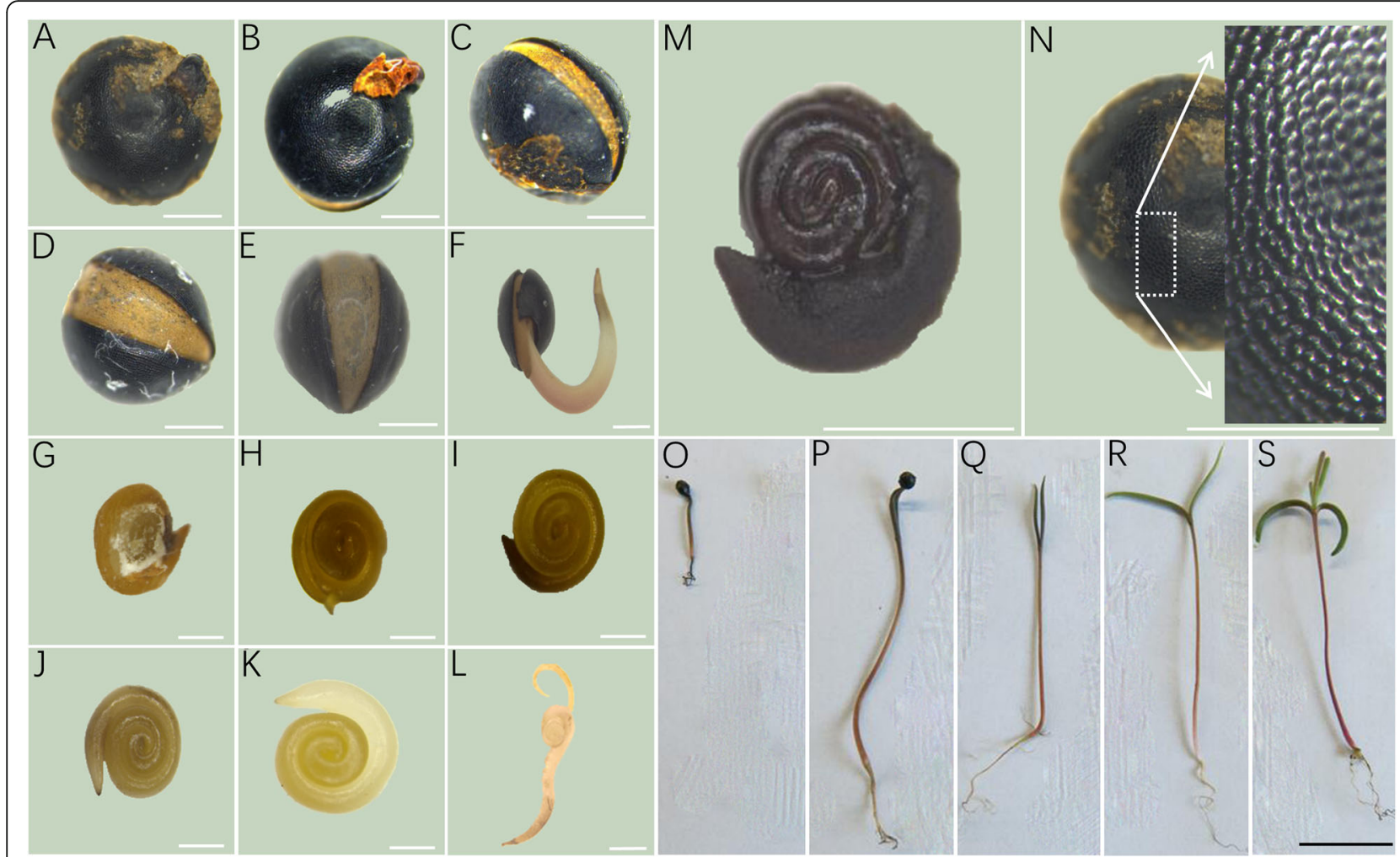

Fig. 1 Seed structure and seed germination pattern of Suaeda salsa. a-f Endocarp appearance and early germination pattern of Suaeda salsa. Bar $=0.5 \mathrm{~mm}$. $\mathbf{g}$-I Seed germination pattern at different stages of planospiral embryo. Bar $=0.5 \mathrm{~mm}$. $\mathbf{m}$ The Seed treated with $\mathrm{KI} / \mathrm{I}_{2}$ for the starch test. $\mathrm{Bar}=0.5 \mathrm{~mm}$. $\mathbf{n}$ Endocarp having honeycomb-like structure. Bar $=0.5 \mathrm{~mm}$. o-s Epigeal germination pattern of Suaeda salsa. Figures showed the seedlings at $48,60,72 \mathrm{~h}$, and 5 and 40 days after germination. Bar $=1 \mathrm{~cm}$

main stem. The leaves (Fig. 2b) and stems (Fig. 2c) from five different positions on one plant are displayed as well.

The mature flowers of Suaeda salsa are spherical or nearly spherical, with a diameter of $2 \pm 0.2 \mathrm{~mm}$ (Fig. 3e). They usually emerge directly on the main and lateral stems. Most of Suaeda salsa flowers are hermaphroditic, sometimes female flowers could be observed. Hermaphroditic Suaeda salsa flowers are composed of four whorls: the inner first whorl possesses gynoecium containing only one pistil with two to three stigmas; the second whorl has five stamens, each stamen possesses two pollen sacs; the third whorl contains five green petals. Interestingly, the petals are similar to the canonical calyxes because of the existence of chlorophyll. Even though five calyxes could be observed in the outer whorl, they are transparent and significantly degraded.

To accurately describe the flower development of Suaeda salsa, we observed the inflorescence stages of Suaeda salsa. According to its flower bud development characteristics, the inflorescence development was divided into five stages. Stage I (100-110 DAG): the flower buds originate from the main stems and branches, and the stamens are invisible (Fig. 3a). Stage II (110-130
DAG): the flower buds grow rapidly, and reach a maximum size, the petals were closely connected, not cracked, and the stigmas were lower than the stamens (Fig. 3b). Stage III (130-140 DAG): the petals begin to split; 1 or 2 stamens are visible. The lengths of stigmas and stamens are the same (Fig. 3c). Stage IV (140-145 DAG): the petals are completely cracked; 5 stamens are naked and light green (Fig. 3d). Stage V (145-155 DAG): the stamens mature, the colour is from light green to yellow, the stigmas are longer than the stamens (Fig. 3e).

We further dissected the flower buds from these five stages and measured the size of the flower organs. As shown in Fig. 3, A-E are the flower buds at five developmental periods, F-J are ovaries at five developmental periods, $\mathrm{K}-\mathrm{O}$ are stamens at five developmental periods, $\mathrm{P}$ $\mathrm{T}$ are petals at five developmental periods. U-Y are calyxes at five developmental periods. The quantification data of different floral parts during these five developmental stages were shown in Additional file 1: Table S1.

\section{Male gametophyte development of Suaeda salsa}

Gametogenesis is a fundamental and critical step in plant life cycles [23], which contributes to the formation of the male gametophyte (pollen) in male organ anther and 


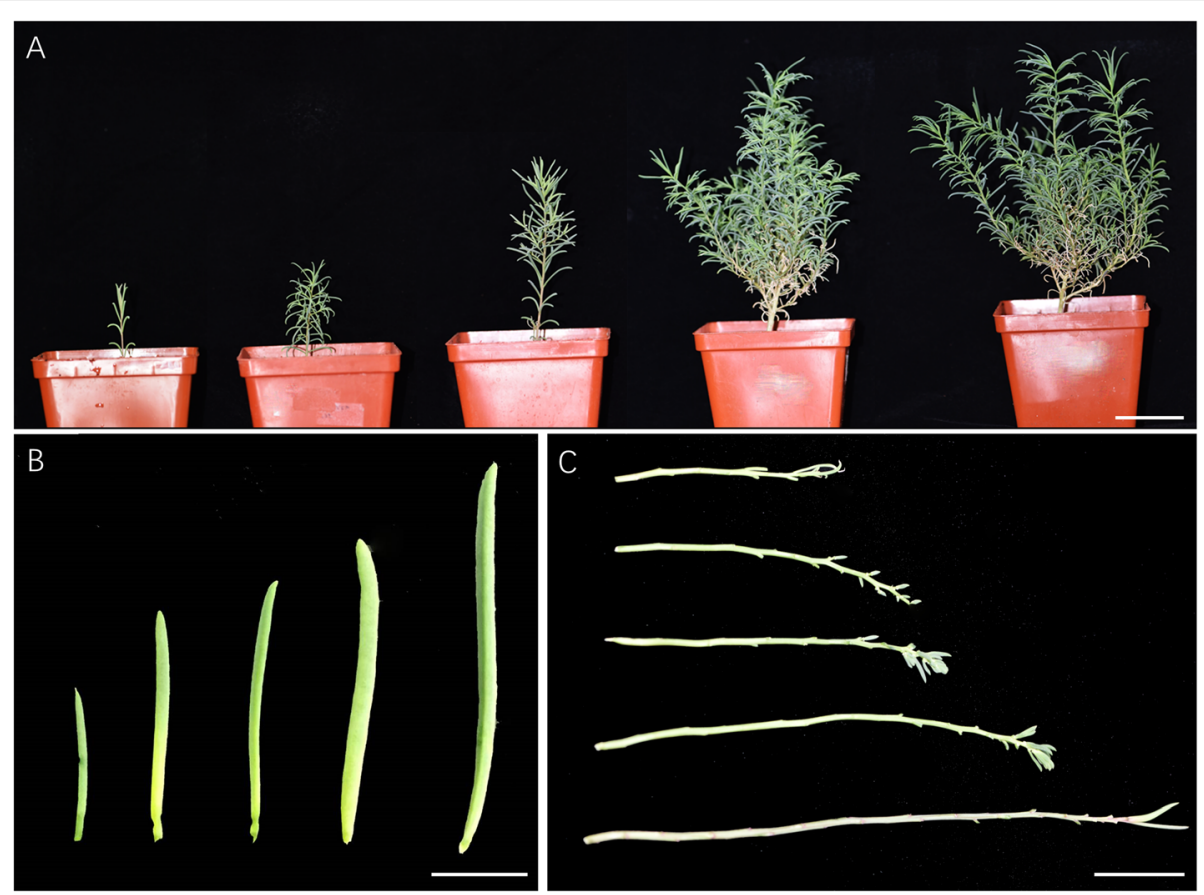

Fig. 2 Leaves, stems, and plants of Suaeda salsa at five developmental stages. a The whole plant of 10-, 20-, 40-, 80-, and 100-days old Suaeda salsa grown in the greenhouse ( $\mathrm{Bar}=5 \mathrm{~cm}$ ). b The 5 leaves of 100-days old Suaeda salsa (Bar $=2 \mathrm{~cm}$ ). c The stems of 100-days old Suaeda salsa grown in the greenhouse $(\mathrm{bar}=3 \mathrm{~cm})$

female gametophyte (embryo sac) in female organ ovule. Although the morphology of mature pollen of Suaeda salsa, including pollen diameter, pore number, pore diameter, etc., have been investigated and reported [24], its male gametophyte development process remains undescribed. To this end, we observed the pollen development of Suaeda salsa, which was compared to that of the model plant Arabidopsis subsequently. The stamens of 5 stages (stage I to stage V: pollen mother cells, tetrad, uninucleate microspore, binucleate pollen, and mature pollen stage) were selected for observation by DIC (Fig. 4a-e) and inflorescence microscopies (Fig. 4f-j). The development process can be described as follows. The pollen development starts with the division and differentiation of germline cells into pollen mother cells (PMC) (Fig. 4a, f). Following the meiosis, PMC generates four haploid microspores (Fig. 4b, g) that develop into mononuclear microspore (Fig. 4c, h). The mononuclear microspore gives rise to binucleate pollen after an asymmetric mitotic division (pollen mitosis I, PMI). The binucleate pollen consists of two cells, a larger (vegetative cell) and a smaller (generative cell) (Fig. 4d, i). The second miotic cell division (pollen mitosis II, PMII) of generative cell generates the trinucleate pollen grain. Within the cytoplasm of the bigger vegetative cell, the trinucleate pollen grain contains two smaller sperm cells (Fig. 4e, j). As compared to the male gametophyte of Arabidopsis (Fig. $4 \mathrm{k}-\mathrm{t}$ ), those observations showed that the pollen development process of Suaeda salsa is similar to that of the model plant Arabidopsis [25].

\section{Female gametophyte development of Suaeda salsa}

The female gametophyte is crucial for the sexual reproduction of higher plants [26]. Identification of the developmental type of female gametophyte can promote understanding and carrying out the process of sexual reproduction and hybridization in plants. Taking the developmental process of female gametophyte in Arabidopsis as a control (Additional file 3: Figure S1), we observed the female gametophyte development process of Suaeda salsa using WCLSM (Whole-mount-stain clearing laser scanning confocal microscopy) theology. The results showed that the female gametophyte development of Suaeda salsa could also be divided into seven stages: Stages I to VII. The development of female gametophyte first begins with megaspore mother cells (MMC, Fig. 5a). At the next stage, compared with the MMC period, the outer integument has completely wrapped the embryo sac, no obvious nuclei can be observed (Fig. 5b). We speculated that this is the meiosis stage, which will give rise to a functional megaspore (FM, Stage I, Fig. 5c). Next, FM undergoes mitosis to form two nuclei (Stage II, Fig. 5d). And soon, the two cells move to each pol, respectively (Stage III, Fig. 5e). Next, the 2 nuclear embryo sac undergo a mitosis to form a 4-nuclear embryo sac (Stage IV, Fig. 5f), and 

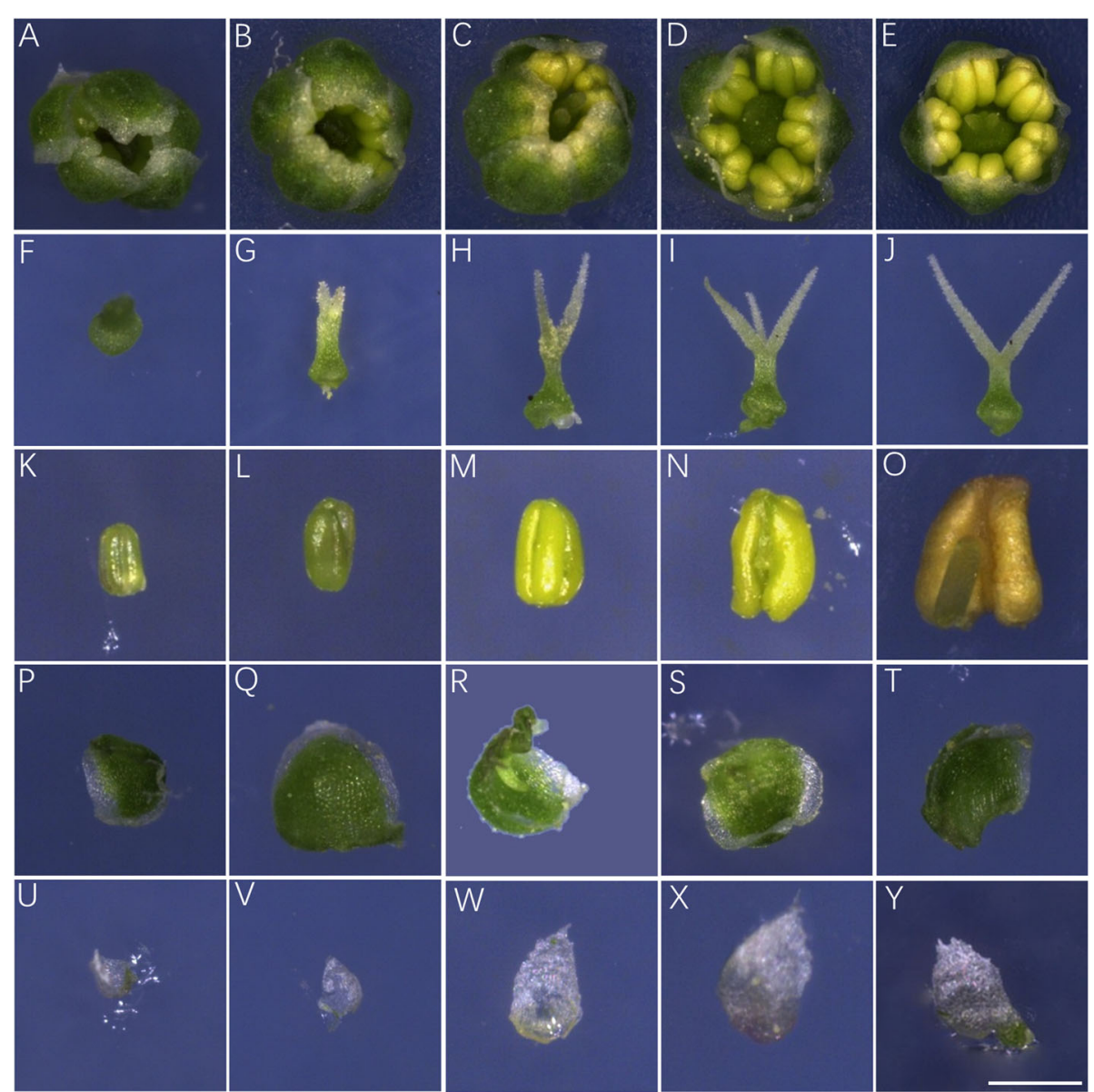

Fig. 3 The floral organs of Suaeda salsa at five developmental stages. The figure showed the flower buds (a-e), pistils (f-j), stamens (k-o), petals (p-t) and calyxes (u-y) at five developmental stages. Bars $=500 \mu \mathrm{m}$

finally the 4-nuclear embryo sac undergoes a mitosis to form a mature embryo sac comprised of seven cells, and 8 nuclei including 2 synergid cells, 1 egg cell, 2 polar nuclei, and 3 anti-pod cells (Stage V Stage VI, Fig. 5g). When mature, three antipodal cells degenerate, and two polar nuclei fuse into a central cell (StageVII, Fig. 5h). In the sexual reproduction of angiosperms, two sperms fuse with the egg cell and central cell, respectively. The results showed that the development process of Suaeda salsa belongs to the Sputum sac type, similar to that of the model plant Arabidopsis.

\section{Diploid Suaeda salsa has nine pairs of chromosomes}

Studies on chromosomal behaviour and pairing during meiosis of pollen mother cells play an essential role in plant genomic analysis and determination of polyploid types. Observation of chromosomal behaviour during plant meiosis often helps to identify plant ploidy levels [27], In recent years, the chromosome number of many species have been determined by observing the meiosis of pollen mother cells [28]. For Suaeda salsa, several reports have given different chromosome counts [29]. To confirm the chromosome number of our Suaeda salsa cultivar. The chromosome spreads of microsporophytes were prepared and observed under the microscope. As shown in Fig. 6, we found 18 chromosomes in metaphase of meiosis I (Fig. 6a). Meanwhile, two sets of 9 chromosomes were observed in dyad cells in metaphase of meiosis II (Fig. 6b). Those observations indicated that the diploid Suaeda salsa has nine pairs of chromosomes $(2 \mathrm{n}=18)$.

\section{The genome size of Suaeda salsa is approximately 437.5} MB

Estimation of the genome size in a species by measuring the DNA content of the nuclei is of considerable significance not only for the molecular, cytogenetic, and genome sequencing of the species but also for the study of plant phylogenetic evolution [30]. The genome size of Suaeda salsa was estimated through flow cytometry using Arabidopsis as reference. We first detected 4 peaks (2C, 4C, 8C, and 16C) for Arabidopsis mature leaves with the fluorescence strength of 24, 48, 96, and 192 

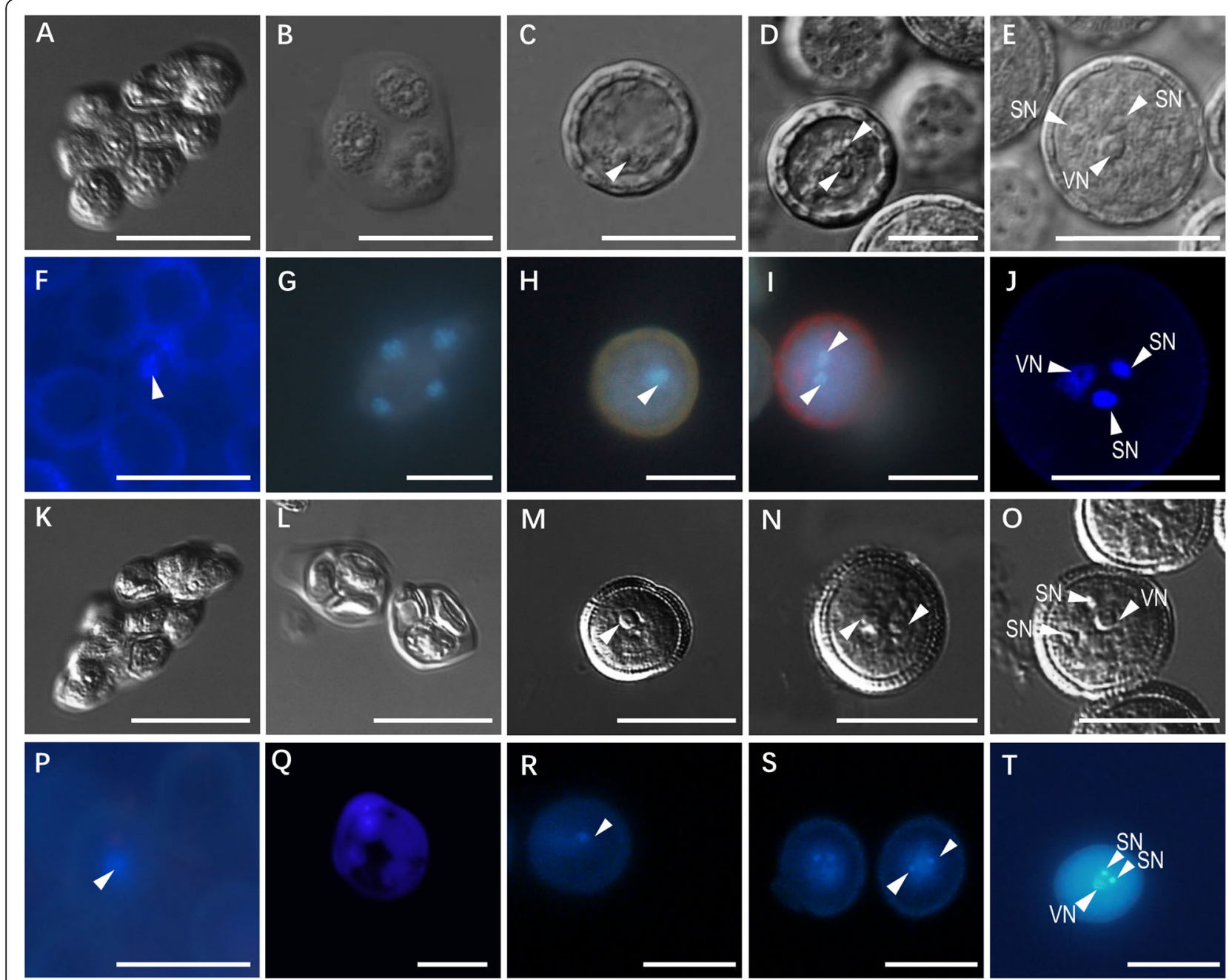

Fig. 4 The male gametophyte development of Suaeda salsa (a-j) and Arabidopsis (k-t). The pollen development observations under the DIC microscope $(\mathbf{a}-\mathbf{e}, \mathbf{k}-\mathbf{o})$ and fluorescence microscope with DAPI staining $(\mathbf{f}-\mathbf{j}, \mathbf{p}-\mathbf{t})$. For each observation, five development stages are shown: pollen mother cell stage ( $\mathbf{a}, \mathbf{f}, \mathrm{k}$ and $\mathbf{p})$, four haploid microspores stage $(\mathbf{b}, \mathbf{g}, \mathbf{I}$ and $\mathbf{q})$, uninucleate microspore stage $(\mathbf{c}, \mathbf{h}, \mathbf{m}$ and $\mathbf{r})$, binuclear pollen stage $(\mathbf{d}, \mathbf{i}, \mathbf{n}$ and $\mathbf{s})$ and tricellular pollen stage $(\mathbf{e}, \mathbf{j}, \mathbf{o}$ and $\mathbf{t})$ are shown respectively. $\mathrm{SN}$, sperm nucleus, VN, vegetative nucleus. Bar $=20 \mu \mathrm{m}$

(Fig. 7a), whilst, two peaks ( $2 \mathrm{C}$ and $4 \mathrm{C}$ ) with the fluorescence strength of 84 and 168 were detected for leaf nuclei of Suaeda salsa under the same parameters (Fig. 7b). The standard deviation of the fluorescence strength of $2 \mathrm{C}$ peak is 5.56 (Additional file 4 Figure. S2). Taking the fact that the genome size of Arabidopsis is proximately $125 \mathrm{MB}$, we estimated that the genome of Suaeda salsa is $437.5 \pm 28.96 \mathrm{MB}$.

\section{Discussion}

Salinity and alkalinity are among major stress cues limiting crop growth and productivity. Soil salinization and alkalization have become a global environmental problem that severely affects the sustainability of agriculture. The main reason for the increase in the area of deteriorated land is human activity and climate change [6]. The halophytes are the species withstanding high salt concentrations that kill $99 \%$ of other glaucophytes [31]. One type of halophyte, usually dicotyledonous, shows optimal growth at a high $\mathrm{NaCl}$ concentration, while the other types of halophytes, generally grow optimally in the absence of salt or at a low $\mathrm{NaCl}$ concentration [32] As the degree of salinization of cultivated land has intensified, researchers are paying more attention to the study of halophytes. According to the statistics, there are about 587 halophytic species in China [33], among which Suaeda salsa is the most typical one. The growth of Suaeda salsa is significantly stimulated by $200 \mathrm{mM} \mathrm{NaCl}$ [8], showing significant salt-tolerance. Additionally, the nutritive value of Suaeda salsa mentioned above makes it star species attracting the attention of biologists working on salt tolerance improvement of cultivated crops. Recently, several studies on Suaeda salsa have been published focusing on physiology, nutrition, and 


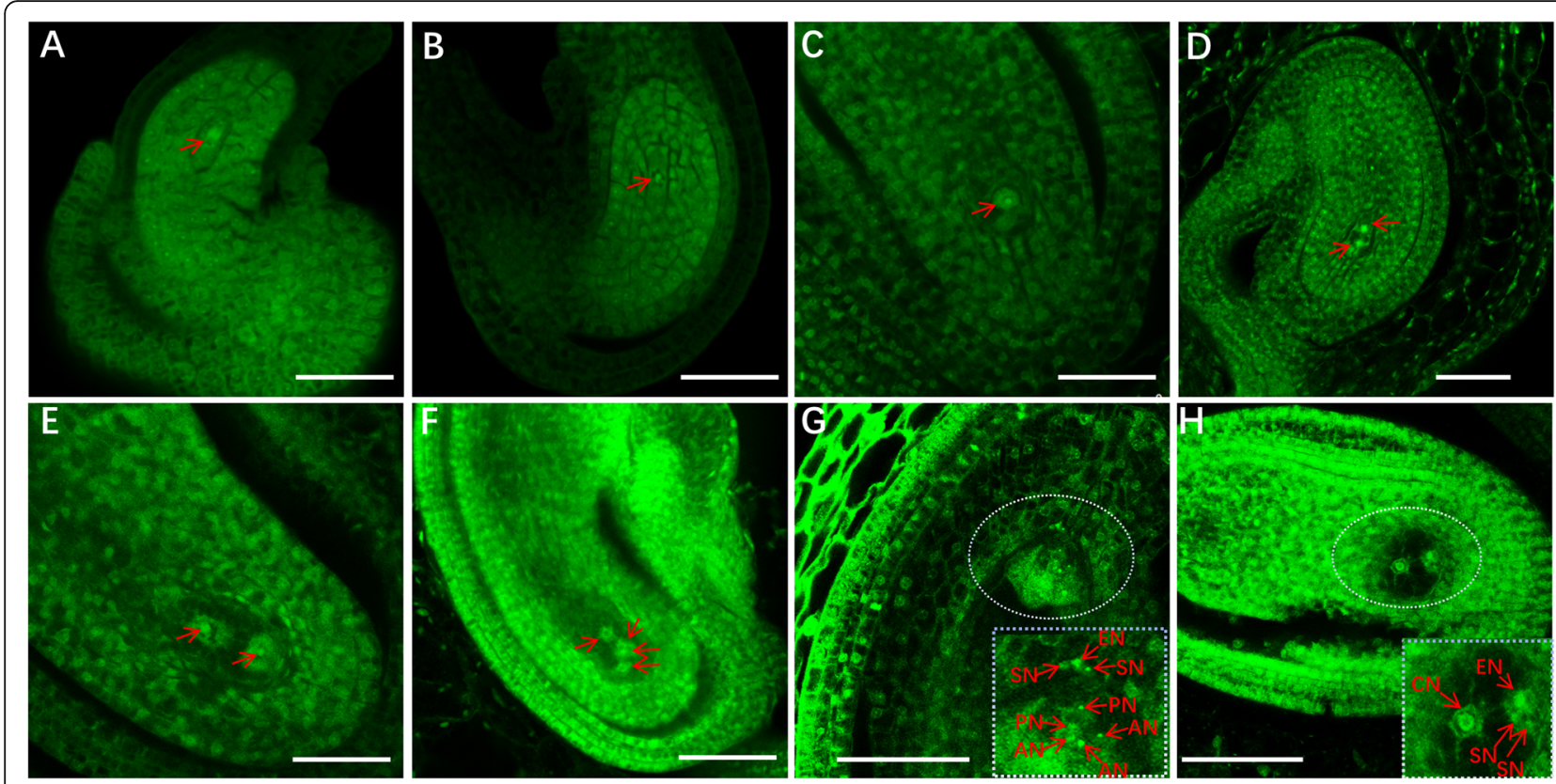

Fig. 5 The female gametophyte development of Suaeda salsa. a Embryo sac with megaspore mother cell, the arrowhead denotes the megaspore mother cell nucleus. b Putative meiosis stage. c Mono-nuclear embryo sac, FG1 embryo sac, the arrowhead denotes the functional megaspore. $\mathbf{d}$ Early bi-nuclear embryo sac, the arrowhead denotes the nucleus after division, FG2. e Later bi-nuclear embryo sac, the arrowhead denotes the nucleus after division, FG3. f Tetra-nuclear embryo sac, FG4. g Medium eight-nuclear embryo sac. FG5 FG6, the rectangular part in the right corner is an enlarged view of the ellipse part. $\mathbf{h}$ Later eight-nuclear embryo sac, three antipodal cells have degenerated, FG7, rectangular part in the right corner is an enlarged view of the ellipse part. A-E: Bars $=20 \mu \mathrm{m}$. F-G: Bars $=50 \mu \mathrm{m}$. AN, Antipodal cell nucleus. PN, Polar nucleus. CN, Central cell nucleus, EN, Egg cell nucleus. SN, Synergid cell nucleus

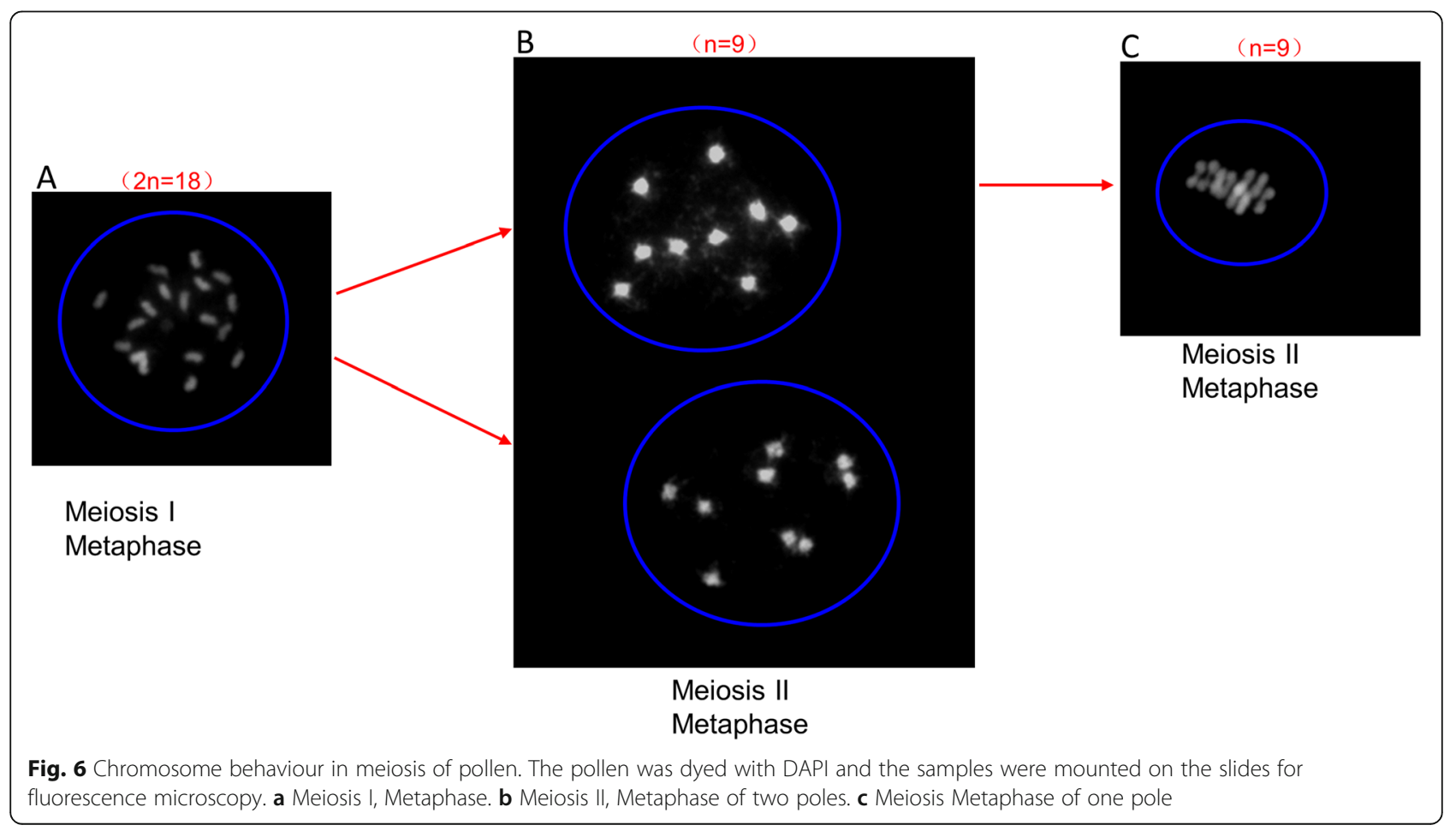



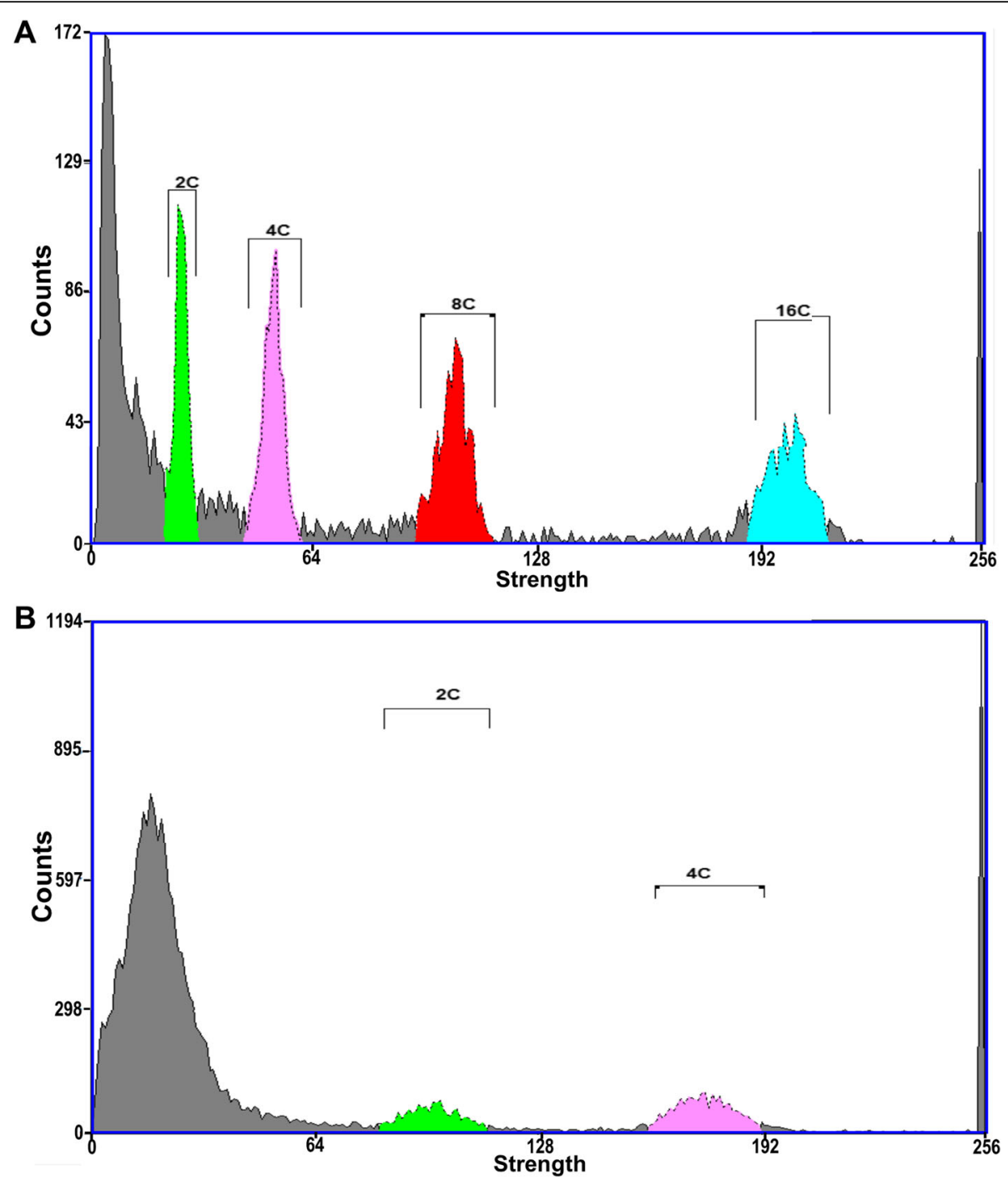

Fig. 7 The estimated genome size of Suaeda salsa was $437.5 \mathrm{Mb}$ by flow cytometry. a The flow cytometry figure of $A$. thaliana leaf showed four peaks: $2 C=24,4 C=48,8 C=96$, and $16 C=192$. b The flow cytometry figure showed the $2 C$ and $4 \mathrm{C}$ peaks of suaeda salsa leaf, $2 C=84$ and $4 C=$ 168. The genome size of Suaeda salsa is approximate $437.5 \mathrm{MB}$

transcriptome [12, 20,34]. However, to our knowledge, studies on the fundamental biological characteristics of Suaeda salsa are rarely reported until today.

A seed is an embryonic plant enclosed in a protective outer covering [35]. Yielding seeds have been an important development in the sexual reproduction and the success of gymnosperm and angiosperm plants during the evolution, compared to the primitive plants such as ferns, mosses, and liverworts [36]. The seed of Suaeda salsa is of typical type with a tough seed coat (Fig. 1a, n). This characteristic is an adaption of Suaeda salsa to drought and salinity conditions in the seashore, which could prolong the dormancy and is beneficial for the diffusion prorogation of the species. Seed germination in plants mainly is three types: Hypogeal Germination, Epigeal Germination and, Vivipary (Viviparous
Germination). When the Suaeda salsa seeds are germinating, the hypocotyl significantly elongates before the emergence of true leaves and brings the cotyledon above the soil (Fig. 1q-s), showing its epigeal germination type. The model plant Arabidopsis, and most other dicots species such as castor, cotton, papaya, onion also belong to epigeal germination type [37].

One characteristic of land plants is the alternation of generations, which is also known as metagenesis. Metagenesis is a type of life cycle that occurs in plants and algae in the Archaeplastida and the Heterokontophyta with distinct sexual haploid and asexual diploid stages [38]. Liverworts, mosses, and hornworts are gametophyte-dominant, while the seedless vascular plants and angiosperms are sporophyte-dominant. Suaeda salsa gametophyte is much reduced to the 
minimum of several cells and relies on sporophyte to obtain nutrition [39]. The haploid female and male gametophytes are essential reproductive units of flowering plants [35]. Male gametophyte development begins with the division of a sporophyte cell. In this study, we described the male gametophyte development of Suaeda salsa with five developmental stages, from microspore mother cell to mature pollen containing three cells (Fig. 4). Since two sperms have already formed in the mature pollen grains, the development of male gametophyte of Suaeda salsa belongs to the minority type, which is represented in $\sim 30 \%$ of plants. The mature pollen grain of majority plants $(\sim 70 \%$, for instance, plants from Solanaceae and Liliaceae) contains only two cells, one vegetative and one generative, and the latter one undergoes the second mitosis just after pollen germination, giving rise to two sperms required for double fertilization [26]. The female gametophyte is a unique structure comprised of quite a few cells and contains the sexual cells [40]. A well-developed female gametophyte is the basis of plant reproduction. Generally, more than 15 different patterns of female gametophyte have been described in angiosperms, which could be classified into three major types: Monosporic (Polygonum) type, Bishopric (Alisma) type, and Tetrasporic (Drusa) type [35]. Although the mature pollen morphology has been reported a decade ago [41], this is the first time to observe and describe the male gametophyte development in Suaeda salsa.

The observation of the female gametophyte development of Suaeda salsa is challenging. At first, we attempted to reveal its development process through DIC microscopy. However, the experimental results indicated that this method is not quite effective because the complete development process cannot be observed due to the dense embryo sac structure. Partial development stages of female gametophyte development were shown in Additional file 5: Figure S3. We also tried the method of resin section. Unfortunately, we could either not obtain a set of images shown the complete development process of female gametophyte development of Suadea salsa (Additional file 6: Figure S4), probably due to the thin oval wall and the limited number of generative cells in one ovule. Eventually, taking advantage of WCLSM (Whole-mount-stain clearing laser scanning confocal microscopy) technology, we successfully observed the development process of the female gametophyte of Suaeda salsa. The observations support that the female gametophyte development pattern of Suaeda salsa belongs to Polygonum type (Fig. 5). It has been reported that the plants from family of Brassicaceae (e.g., Arabidopsis, Capsella, Brassica), Gramineae (e.g., maize, rice, wheat), Malvaceae (e.g., cotton), Leguminoseae (e.g., beans, soybean), and Solanaceae (e.g., pepper, tobacco, tomato, potato, petunia) [42-45]) showed Polygonum type female gametophyte development. The observation in this study provides a new example from family Amaranthaceae, which also adopts the Polygonum development type of female gametophyte. The healthy development of the male and female gametophytes and the successful completion of the double fertilization directly determine the seed yield. Suaeda salsa, as an excellent potential oil crop, scientists nowadays are trying to increase its yield. Here, we revealed the developmental types of male and female gametophytes, which would lay an important foundation for molecular breeding of Suaeda salsa.

The chromosome is the vector of genetic information in eukaryotes, it is a combination of Deoxyribonucleic acid (DNA) and protein molecules with part or all of the genetic material of an organism. Typically, the number of chromosomes is constant for all individuals of a specific species, and this is of great importance in determining the phylogeny and taxonomy of the species [46]. Genome is the sum of total genetic material in the haploid set of chromosomes. For most angiosperms, the somatic cell of sporophyte contains two haploid sets of genomes, while the generative cell of gametophyte only has one set. Even though several databases are focusing on the chromosome number and genome size, the extensive observation and investigation on the chromosome number and genome size of specific species are still imperative and of great significance. The chromosome number of Suaeda salsa has been reported in the 1950s and 1960s [41, 47]. In the Chromosome Count Database (http://ccdb.tau.ac.il/home/), 16 Chromosome number records of this species (Accepted name: Suaeda maritima subsp. salsa (L.) Soó) were deposited with the $2 \mathrm{n}=$ 18, 36, 54, respectively (Additional file 2: Table S2) [29]. The inconsistency on chromosome counts records of this species is probably due to the different ecotypes that were investigated. Most of the records have 36 or 54 chromosomes were from Siberia area [48-52]. To confirm this significant characteristic of Suaeda salsa of our ecotype, we observed its chromosome behaviour during male gametogenesis. Our results showed that the chromosome number of Suaeda salsa is $2 \mathrm{n}=18$ (Fig. 6). It has been reported that most of the species form Chenopodiaceae have relatively stable chromosome organization with the basic number of 9 . The exceptions are Camphorosma and Spinacia, whose basic chromosome numbers are 6 . Our observation is consistent with this conclusion [53]. Taken together, we can speculate that $\mathrm{X}=9$ might be the original basic chromosome number of Dianthus order. Moreover, the estimated genome size of Suaeda salsa haploid is approximately $437.5 \pm$ 28.96 MB through flow cytometry in this study (Fig. 7). The results from chromosome number observation and genome size estimation provide useful information for the genomic research on Suaeda salsa. 


\section{Conclusions}

In this study we observed the seed, plant and floral organ morphology and development of Suaeda salsa, the results indicating that the seed germination pattern of Suaeda salsa belongs to epigeal germination, and the developments of both male and female gametophytes of Suaeda salsa are similar to those of model plant Arabidopsis. The chromosome number of Suaeda salsa is $2 \mathrm{n}$ $=19$. The genome size of Suaeda salsa is approximately 437.5 MB estimated by FCM. The observations and results discussed in this article will provide us with a better understanding of the salt (stress)-tolerant plant and insights into future research on Suaeda salsa.

\section{Methods}

\section{Plant materials and growth conditions}

Suaeda salsa seeds were provided by Yancheng Lvyuan Salt Soil Agricultural Technology Co. Ltd., Yancheng, Jiangsu, Southeast China (http://www.ychpz.com/index. asp). Seeds were treated with $0.03 \%$ Gibberellin and planted at $25^{\circ} \mathrm{C}$ in the greenhouse with $16 / 8 \mathrm{~h}$ of lightdark photoperiod cycle. The Suaeda salsa plants growing in the greenhouse are flowering during summer. The wildtype Arabidopsis thaliana (L.) Heynh (Col-0; CS60000) was obtained from the Arabidopsis Biological Resource Center (Columbus, OH, USA; https://abrc.osu.edu/). Arabidopsis plants were grown in a greenhouse with $60 \%$ humidity under a $16 \mathrm{~h}$ light $/ 8 \mathrm{~h}$ dark photoperiod cycle at $22^{\circ} \mathrm{C}$. Flower buds of different developmental stages were used from matured plants for observation of male and female gametophyte development.

\section{Plant morphology observation and measurement}

The photographs showing the plant morphology of Suaeda salsa were taken at 10, 20, 40, 80,100 days after germination (DAG). The leaves and lateral stems of Suaeda salsa from 100 DAG were dissected and photographed using a Nikon D7200 digital camera. The flower buds at different developmental stages were picked up with a tweezer. The floral organs were dissected with 0.1 $\mathrm{mm}$ syringes under an anatomical microscope and then placed on agar plates $(0.8 \%)$ for photographing. The images were taken through a Leica DFC550 microscope, and the measurements were performed using ImageJ software $(\mathrm{NIH})$.

\section{Observation of male gametophyte development}

Male gametophyte development was observed by both differential interference contrast (DIC) microscopy and inflorescence microscopy. For DIC microscopy, the pollens of different development stages were obtained and cleared by chloral hydrate solution (chloral hydrate: $\mathrm{H} 2 \mathrm{O}$ : glycerol = 8: 2: 1) on slides. Cleared anthers were imaged using a BX63 microscope (Olympus) with DIC optics. For inflorescence microscopy, the samples were decoloured in $25 \%$ acetic acid $75 \%$ ethanol solution for three times and stained with 4', 6-Diamidino-2-Phenylindole (DAPI), following the method described by Yang et al. (2009) and Dou et al. (2011) [54, 55]. The nuclei of male gametophytes were then observed under Leica MZ10F and DM2500 microscopes.

\section{Observation of female gametophyte development}

The flower buds at different developmental stages were collected and fixed in FAA solution (50\% ethanol: glacial acetic acid: formaldehyde $=89: 6: 5)$ for $24 \mathrm{~h}$. The samples were then washed with $50 \%$ ethanol twice and transferred into $70 \%$ ethanol for storage. The ovaries were dissected from the fixed florets under a dissecting microscope. WCLSM (Whole-mount-stain clearing laser scanning confocal microscopy) theology $[56,57]$ was applied to observe the female gametophyte development of Suaeda salsa. The dissected ovaries were hydrated sequentially in 50\% ethanol, 30\% ethanol and distilled water, and mordanted in $2 \%$ aluminum potassium sulphate for 20 min followed by staining with eosin (10 $\mathrm{mg} / \mathrm{L}$ in $4 \%$ sucrose solution) for $10-12 \mathrm{~h}$. The stained samples were then retreated with $2 \%$ aluminum potassium sulphate for $20 \mathrm{~min}$ to remove the dye from the wall of the ovaries. After three times of rinsing with distilled water, the samples were treated successively with 30, 50, 70, 90 and 100\% ethanol for $20 \mathrm{~min}$ each for dehydration. For cleansing, the dehydrated samples were treated in ethanol-methyl salicylate solution $(\mathrm{V}: \mathrm{V}=1: 1)$ for $2 \mathrm{~h}$, and then kept in methyl salicylate solution for at least $2 \mathrm{~h}$. The cleansed samples were placed on concavity slides and mounted with fingernail polish and photographed under a Leica SP8 Laser scanning confocal following the reported method [58].

\section{Chromosome number analysis}

The pollen grains with $0.3-0.5 \mathrm{~mm}$ in diameter were collected and used for chromosome number observation. The chromosome spreads of microsporophytes were prepared as described previously by [59] and stained with $1.5 \mu \mathrm{g} / \mathrm{ml}$ 4,6-diamidino-2-phenylindole (DAPI). Images of chromosome spreads were taken using a Zeiss (Model) microscope.

\section{Genome size estimation by FCM}

Since Arabidopsis thaliana has been sequenced, and its genome size is known $(n=125 \mathrm{MB}$, The Arabidopsis genome initiative, 2000) [60], it was selected as reference in this analysis. The fresh leaves of tested species were dissected from the plants and chopped by a very sharp razor blade in $1 \mathrm{ml}$ Arumuganathan and Earle Buffer [61]. The suspension was then filtered through a $30 \mu \mathrm{m}$ mesh and 1:100 DAPI $(10 \mathrm{mg} / \mathrm{ml})$ was added for nuclei 
staining. The sample was left for at least 5 min before being analyzed using MoFlo XDP Sorter (Beckman). Typically, 4000-5000 nuclei were measured in each run. The inflorescence strength of different peaks of the Arabidopsis and Suaeda salsa were recorded by the instruments and the $\mathrm{C}$ - values for different peaks of DNA histogram were generated by the Beckman software. The inflorescence strength of the $2 \mathrm{C}$ peak was used for estimating the genome size of Suaeda salsa [62].

\section{Additional files.}

Additional file 1: Table S1. The size of each organ at five

developmental stages.

Additional file 2: Table S2. The chromosome number records of Suaeda salsa (L.) Pall. exported from Chromosome Counts Database (CCDB).

Additional file 3: Figure S1. Female gametophyte development of Arabidopsis under the DIC field.

Additional file 4: Figure S2. The flow cytometry assay of Suaeda salsa. The figure showed the standard deviation of $2 \mathrm{C}$ peak.

Additional file 5: Figure S3. Female gametophyte development of Suaeda salsa under the DIC field.

Additional file 6: Figure S4. Ovary section of Suaeda salsas from early to late stage.

\section{Abbreviations}

FCM: Flow cytometry; MB: Mega Base pair; WCLSM: Whole-mount-stain clearing laser scanning confocal microscopy

\section{Acknowledgments}

We thank Chunyin Zhang for providing the original seeds of Suaeda salsa.

\section{Authors' contributions}

$Y C$. and $Y Q$. initiated and designed the research. $Y C, P Y, L Z, S P, Q Z$, Zeyun- $L$ and $J \mathrm{~L}$ performed the experiments. WL, JX, Zhibin-L, Li-L, and $X H$ analyzed the data. $H Z, G L, J M$, and Lei-L helped with a critical discussion on the work. YC and PY wrote the paper. YQ and MA revised the paper. All authors discussed the results and approved the final version of the manuscript.

\section{Funding}

Y.Q. is supported by a grand from National Science Foundation, China (U1065212) and Guangxi Distinguished Experts Fellowship. Y.C. is supported by a grant from National Science Foundation, China (31671267), a grant from state key laboratory of Ecological Pest Control for Fujian and Taiwan Crops (SKB201708), and a grant from Natural Science Foundation of Fujian Province (2018 J01704). The Funding bodies were not involved in the design of the study and collection, analysis, and interpretation of data and in writing the manuscript.

\section{Availability of data and materials}

All data and material are provided in the manuscript and Additional Files.

\section{Ethics approval and consent to participate}

Not applicable.

\section{Consent for publication}

Not applicable.

\section{Competing interests}

The authors declare that they have no competing interests.

\section{Author details}

${ }^{1}$ State Key Laboratory of Ecological Pest Control for Fujian and Taiwan Crops, College of Plant Protection, Fujian Provincial Key Laboratory of Haixia Applied
Plant Systems Biology, Center for Genomics and Biotechnology, Fujian Agriculture and Forestry University, Fuzhou 350002, China. ${ }^{2}$ College of Life Science, Fujian Agriculture and Forestry University, Fuzhou 350002, China. ${ }^{3}$ State Key Laboratory for Conservation and Utilization of Subtropical Agro-Bioresources, Guangxi Key Lab of Sugarcane Biology, College of Agriculture, Guangxi University, Nanning 530004, China. ${ }^{4}$ College of Resources and Environment, Fujian Agriculture and Forestry University, Fuzhou 350002, China. ${ }^{5}$ College of Crop Science, Fujian Agriculture and Forestry University, Fuzhou 350002, China. ${ }^{6}$ Key Laboratory of Biogeography and Bioresources in Arid Land, Xinjiang Institute of Ecology and Geography, Urumqi 83000, China. ${ }^{7}$ State Key Laboratory of Protein and Plant Gene Research, Peking-Tsinghua Center for Life Sciences, School of Life Sciences and School of Advanced Agricultural Sciences, Peking University, Beijing 100871, China.

Received: 9 July 2019 Accepted: 16 October 2019

Published online: 06 November 2019

\section{References}

1. Yu Y, Huang WG, Chen HY, Wu GW, Yuan HM, Song XX, Kang QH, Zhao DS, Jiang WD, Liu Y, Wu JZ, Cheng LL, Yao YB, Guan FG. Identification of differentially expressed genes in flax (Linum usitatissimum L) under salinealkaline stress by digital gene expression. Gene. 2014;549(1):113-22.

2. Goossens R, Van Ranst E. The use of remote sensing to map gypsiferous soils in the Ismailia province (Egypt). Geoderma. 1998;87(1):47-56.

3. Wang ZQ. Salt-affected soil in China. Beijing: Science Press; 1993. [in Chinese]

4. Wang JL, Huang XJ, Zhong TY, Chen ZG. Review on sustainable utilization of salt-affected land. Acta Geograph Sin. 2011;66(5):673-84.

5. Kawanabe S, Zhu T. Degeneration and conservation of Aneurolepidium. Chinense grassland in northern China. J Jpn Grassland Sci. 1991;37:91-9.

6. Li J, Pu L, Han M, Zhu M, Zhang R, Xiang Y. Soil salinization research in China: advances and prospects. J Geogr Sci. 2014;24(5):943-60.

7. Yang C, Shi DC, Wang D. Comparative effects of salt and alkali stresses on growth, osmotic adjustment and ionic balance of an alkali-resistant halophyte Suaeda glauca (Bge). Plant Growth Regul. 2008;56(2):179-90.

8. Song J, Chen M, Feng G, Jia $Y$, Wang B, Zhang F. Effect of salinity on growth, ion accumulation and the roles of ions in osmotic adjustment of two populations of Suaeda salsa. Plant Soil. 2009;314(12):133-41.

9. Shao Q, Han N, Ding TL, Wang BS. Polyclonal antibody preparation and expression analysis of high-affinity $\mathrm{K}^{+}$transporter SsHKT1. J Wuhan Bot Res. 2006;24:292-7.

10. Ma X, Zhang Q, Shi H, Zhu J, Zhao Y, Ma C, Zhang H. Molecular cloning and different expression of a vacuolar $\mathrm{Na}^{+} / \mathrm{H}^{+}$antiporter gene in Suaeda salsa under salt stress. Biol Plant. 2004;48(2):219-25.

11. Han N, Shao Q, Bao HY, Wang BS. Cloning and characterization of a $\mathrm{Ca}^{2+}$ $/ \mathrm{H}^{+}$antiporter from halophyte Suaeda salsa L. Plant Mol Biol Report. 2011;29 (2):449-57.

12. Zhang X, Li M, Yang H, Li X, Cui Z. Physiological responses of Suaeda glauca and Arabidopsis thaliana in phytoremediation of heavy metals. Environ Manag. 2018;223:132-9.

13. Sun JJ, Wang RH, Dai HL, Zhang BW, Dai YC. Research progress on the chemical constituents of Suaeda salsa (L.) and their development and utilization. Shandong Chem Ind. 2018;47:71-2.

14. Zhao HL. Study on edible value of Suaeda salsa (I.) pall. J Anhui Agr Sci. 2010:38:14350-1.

15. Zhang LB, Xu HL, Zhao GS. Salt tolerance of Suaeda salsa and its soil ameliorating effect on coastal saline soil. Soils. 2007;39:310-3.

16. Gu FT. Research in exploiting the green series of edibles-Suaeda Salsa. J Binzhou Edu College. 1999;5:43-8.

17. Ding HR, Hong Z, Yang ZQ, Wang MW, Wang K, Zhu XM. Progress of study on halophyte Suaeda salsa. Acta Agr Jiangxi. 2008;20:35-7.

18. Li HS, Fan YX. Extraction and characteristics analysis of Suaeda salsa seed oil. China Oils Fats. 2010;35:74-6.

19. Shao QL, Xie XD, Zhang FS, Cui HW, Cao ZY. A preliminary study on the artificial cultivation and breeding selection of Suaeda salsa. Chinese J EcoAgri. 2004;12(1):47-9.

20. Shi HQ, Jiang W, Yi D, Liu FY, Yi GY. Study on the preparation of conjugated linoleic acid with S. salsa seed oil and the determination of molecule structures. Food Sci. 2005;26(5):80-4. 
21. Li W, Yamaguchi S, Khan MA, An P, Liu X, Tran LP. Roles of gibberellins and abscisic acid in regulating germination of Suaeda salsa dimorphic seeds under salt stress. Front Plant Sci. 2016;6(1):1235.

22. Wang L, Huang Z, Baskin CC, Baskin JM, Dong M. Germination of dimorphic seeds of the desert annual halophyte Suaeda aralocaspica (Chenopodiaceae), a C4 plant without Kranz anatomy. Ann Bot. 2008;102(5):757-69.

23. Brownfield L, Hafidh S, Durbarry A, Khatab H, Sidorova A, Doerner P, Twell D. Arabidopsis DUO POLLEN3 is a key regulator of male germline development and embryogenesis. Plant Cell. 2009;21(7):1940-56

24. Dehghani M, Akhani H. Pollen morphological studies in subfamily Suaedoideae (Chenopodiaceae). Grana. 2009;48(2):79-101.

25. Mccormick S. Male gametophyte development. Plant Cell. 1993;5(10):1265-75

26. Li LX, Liao HZ, Jiang LX, Tan QY, Zhang X. Arabidopsis thaliana NOP10 is required for gametophyte formation. J Integr Plant Biol. 2018;60(8):723-36.

27. Zhang J, Chen QQ, Zhao X, Wei N. Karyotype analysis and pollen mother cell meiosis observation in taraxacum antungense kitag (asteraceae). Acta Bot Boreali-Occidentalia Sin. 2012;32(12):2419-24.

28. An H, Hu M, Li P, Geng G, Zhang Q, Zhang S. Chromosomal behavior during meiosis in the progeny of triticum timopheevii xhexaploid wild oat. PLoS One. 2015;10(5):e0126398.

29. Rice A, Glick L, Abadi S, Einhorn M, Kopelman NM, Minkov AS, Mayzel J, Chay O, Mayrose I. The chromosome counts database (CCDB) a community resource of plant chromosome numbers. New Phytol. 2015;206(1):19-26.

30. Wang YP, Xiao BY, Xiong WB, Wu SD, Ji AJ, Duan LX. Genome size analysis for Morinda officinalis how using flow cytometry. Trad Chinese Drug Res Clini Pha. 2018;29:657-60.

31. Flowers TJ, Colmer TD. Salinity tolerance in halophytes. New Phytol. 2008; 179(4):945-63.

32. Kafi M, Asadi H, Ganjeali A. Possible utilization of high-salinity waters and application of low amounts of water for production of the halophyte kochia scoparia as alternative fodder in saline agroecosystems. Agr Water Manage. 2010;97(1):139-47.

33. Zhao KF, Song J, Feng G, Zhao M, Liu JP. Species, types, distribution, and economic potential of halophytes in China. Plant Soil. 2011;342(1-2):495509.

34. Jin $H$, Dong $D$, Yang $Q$, Zhu D. Salt-responsive transcriptome profiling of Suaeda glauca via RNA sequencing. PLoS One. 2016;11(3):e0150504.

35. Skinner DJ, Sundaresan V. Recent advances in understanding female gametophyte development. F1000. 2018;7:F1000 Faculty Rev-804. Published 2018 Jun 20. https://doi.org/10.12688/f1000research.14508.1.

36. Li W, Ma H. Gametophyte development. Curr Biol. 2002;12(21):718-21.

37. Sundaresan V, Alandete-Saez M. Pattern formation in miniature: the female gametophyte of flowering plants. Development. 2010;137(2):179-89.

38. Ahmed S, Cock MJ, Pessia E, Luthringer R, Cormier A, Robuchon M, Sterck L, Peters AF, Dittami SM, Corre E, Valero M, Aury JM, Roze D, Peer YV, Bothwell J, Marais GA, Coelho SM. A haploid system of sex determination in the brown alga ectocarpus sp. Curr Biol. 2014;24(17):1945-57.

39. Chehregani A, Malayeri B, Yousefi N. Developmental stages of ovule and megagametophyte in Chenopodium botrys $L$ (Chenopodiaceae). Turk J Bot. 2009;33(2):75-81.

40. Drews GN, Yadegari R. Development and function of the angiosperm female gametophyte. Annu Rev G. 2002;36(1):99-124.

41. Darlington CD, Wylie AP. Chromosome atlas of flowering plants. Kew Bull. 1956;11(2):37.

42. Maheshwari P. An introduction to the embryology of angiosperms. New York: McGraw-Hill; 1950.

43. Willemse MTM, Van WJL. The female gametophyte. In: Johri BM, editor. Embryology of angiosperms. Heidelberg: Springer, Berlin; 1984.

44. Huang BQ, Pierson ES, Russell SD, Tiezzi A, Cresti M. Video microscopic observations of living, isolated embryo sacs of Nicotiana and their component cells. Sex Plant Reprod. 1992;5(2):156-62.

45. Haig D. New perspectives on the angiosperm female gametophyte. Bot Rev. 1990;56(3):236-74.

46. Hammond CM, Stromme CB, Huang H, Patel DJ, Groth A. Histone chaperone networks shaping chromatin function. Nat Rev Mol Cell Biol. 2017;8(3):141-58.

47. Federov AA. Chromosome numbers of flowering plants. Hereditas. 1974;63 (1):328-32.

48. Freitag $\mathrm{H}$, Lomonosova MN. Typification and identity of Suaeda crassifolia, S. prostrata and S. salsa, three often confused species of Suaeda sect. Brezia (Chenopodiaceae, Suaedoideae). Willdenowia. 2006;36(1):21-36.
49. Lomonosova MN, Krasnikov AA, Krasnikova SA. Chromosome numbers of Chenopodiaceae from Siberia. Bot Žhurn. 2001;86(9):145-6.

50. Lomonosova MN, Krasnikov AA, Krasnikova SA. Chromosome numbers of Chenopodiaceae family members of the Kazakhstan flora. Bot Žhurn. 2003; 88(2):134-5.

51. Lomonosova MN. Chromosome numbers of Chenopodiaceae species from Russia and Kazakhstan. Bot Žhurn. 2005;90(7):1132-4.

52. Lomonosova MN. Chromosome numbers of some Chenopodiaceae representatives of the flora of Russia. Bot Žhurn. 2006;91(11):1757-9.

53. Zhang F, Yao Y. Karyotype analysis of Suaeda salsa $(L)$ pall. Shandong Sci. 2013;26:53-5.

54. Yang K, Xia C, Liu X, Dou X, Wang W, Chen L, Zhang X, Xie L, He L, Ma X. A mutation in Thermosensitive male sterile 1 , encoding a heat shock protein with DnaJ and PDI domains, leads to thermosensitive gametophytic male sterility in Arabidopsis. Plant J. 2009;57(5):870-82.

55. Dou XY, Yang KZ, Zhang Y, Wang W, Liu XL, Chen LQ, Zhang XQ, De Y. WBC27, an adenosine tri-phosphate-binding cassette protein, controls pollen wall formation and patterning in Arabidopsis. J Integr Plant Biol. 2011;53(1):74-88.

56. Zhang HH, Feng JH, Lu YG, Yang BY, Liu XD. Observation on formation and development of autotetraploid rice embryo sac using laser scanning confocal microscope. Chinese Elec Micro Socie. 2003:22:380-4.

57. Liu XD, Lu YG, Zhu HL, Xu XB, Feng JH, Xu SX. Abnormal behavior of nuclei and microtubule (MT) organizational changes during embryo sac development in the poly-egg mutant, AP IV of rice. Acta Bot Sin. 2004;46: 829-38.

58. Zhao LH, He J, Cai HY, Lin HY, Li YQ, Liu RY. YangZB, Qin Y. comparative expression profiling reveals novel gene functions in female meiosis and gametophyte development in Arabidopsis. Plant J. 2014;80(4):615-28.

59. Ross KJ, Fransz P, Jones $\mathrm{GH}$. A light microscopic atlas of meiosis in Arabidopsis thaliana. Chromosom Res. 1996;4(7):507-16.

60. The Arabidopsis Genome Initiative. Analysis of the genome sequence of the flowering plant Arabidopsis thaliana. Nature. 2000;408 (6814):796.

61. Zhou Y, Wang H, Gilmer S, Whitwill S, Fowke LC. Effects of co-expressing the plant CDK inhibitor ICK1 and D-type cyclin genes on plant growth, cell size and ploidy in Arabidopsis thaliana. Planta. 2003;216(4):604-13.

62. Doležel J, Bartos J. Plant DNA flow cytometry and estimation of nuclear genome size. Ann Bot. 2005;95(1):99-110.

\section{Publisher's Note}

Springer Nature remains neutral with regard to jurisdictional claims in published maps and institutional affiliations.
Ready to submit your research? Choose BMC and benefit from:

- fast, convenient online submission

- thorough peer review by experienced researchers in your field

- rapid publication on acceptance

- support for research data, including large and complex data types

- gold Open Access which fosters wider collaboration and increased citations

- maximum visibility for your research: over $100 \mathrm{M}$ website views per year

At BMC, research is always in progress.

Learn more biomedcentral.com/submissions 